EXTENDED REPORT

\title{
Synovial tissue inflammation in early and late osteoarthritis
}

\author{
M J Benito, D J Veale, O FitzGerald, W B van den Berg, B Bresnihan
}

Ann Rheum Dis 2005;64:1263-1267. doi: 10.1136/ard.2004.025270

See end of article for authors' affiliations

Correspondence to:

Correspondence to:
Professor B Bresnihan, St Vincent's University Hospital, Elm Park, Dublin 4, Ireland; b.bresnihan@ svcpc.ie

Accepted 7 February 2005 Published Online First 24 February 2005

\begin{abstract}
Objective: To compare selected immunohistological features of inflammation in synovial tissue from patients with early and late osteoarthritis (OA).

Methods: Synovial tissue samples were obtained from 10 patients with knee pain, normal radiographs, and arthroscopic manifestations of OA (early OA), and from 15 patients with OA undergoing knee joint arthroplasty (late OA). Conventional immunohistochemical techniques were used to measure microscopic manifestations of inflammation. The inflammatory cell infiltrate, blood vessel formation, and angiogenic factors, NF- $\kappa$ B activation, expression of tumour necrosis factor $\alpha$ (TNF $\alpha$ ) and interleukin $1 \beta$ (IL1 $\beta$ ), and the presence of cyclo-oxygenase (COX)- 1 and COX-2 were quantified. Fibroblast-like synoviocytes (FLS) were isolated from early and late OA tissue samples to compare in vitro production of prostaglandin $E_{2}\left(\mathrm{PGE}_{2}\right)$ Results: Synovial tissue from patients with early OA demonstrated significantly greater CD4+ $(p=0.017)$ and $C D 68+(p<0.001)$ cell infiltration, blood vessel formation $(p=0.01)$, vascular endothelial growth factor $(p=0.001)$, and intercellular adhesion molecule-1 expression $(p<0.001)$. Numbers of cells producing TNF $\alpha$ and ILI $\beta$ were also significantly greater in early OA $(p<0.001)$. Manifestations of inflammation in early OA were associated with increased expression of the NF- $\kappa B 1(p<0.001)$ and $\operatorname{Rel} A$ $(p=0.015)$ subunits, and with increased COX-2 expression $(p=0.04)$. Cytokine-induced $\mathrm{PGE}_{2}$ production by cultured FLS was similar in both groups.

Conclusion: Increased mononuclear cell infiltration and overexpression of mediators of inflammation were seen in early OA, compared with late OA. Isolated FLS were functionally similar in both groups, consistent with microenvironmental differences in the synovial tissue during different phases of OA. These observations may have important therapeutic implications for some patients during the early evolution of OA.
\end{abstract}

O steoarthritis (OA) is the most common form of arthritis, and is the single most important cause of disability in older adults. ${ }^{1}$ The aetiology of $\mathrm{OA}$ is multifactorial and can include both systemic and local biomechanical factors. ${ }^{2}$ Systemic factors that have been associated with OA include age, sex, racial and genetic susceptibility, bone density, oestrogen levels, and nutritional factors.

Synovial membrane inflammation may also have a role in the pathophysiology of OA. ${ }^{3}$ Magnetic resonance imaging and ultrasonography have demonstrated synovitis in early OA, even in joints where synovitis was not detected clinically. ${ }^{45}$ The occurrence of synovitis after trauma to the knee joint may result in progressive patellofemoral chondropathy. ${ }^{6}$ Immunohistochemical studies have confirmed that synovial tissue from patients with early $\mathrm{OA}$ is characterised by mononuclear cell infiltration, and the production of proinflammatory cytokines and mediators of joint damage. ${ }^{7-9}$ The suggestion that synovial inflammation may be an important aetiological factor in OA was supported by raised serum $\mathrm{C}$ reactive protein levels, which were associated with progression of OA..$^{10-12}$

In this study synovial tissue from patients with very early OA was evaluated for the presence of inflammation. Selected mediators of inflammation were quantified and compared with tissue samples from patients with late OA. The expression of Rel/NF- $\kappa \mathrm{B}$ subunits was also examined. A range of inflammatory activity was seen in both early and late OA. Of interest, the measures of inflammation were significantly greater in the patients with very early OA. These observations suggest that targeted inhibition of proinflam- matory mechanisms during the early phases of OA may benefit some patients.

\section{PATIENTS AND METHODS \\ Patients}

Patients with anterior knee pain for $<1$ year, who were considered to have early OA, were invited to undergo arthroscopic synovial biopsy of the symptomatic joint. All fulfilled the American College of Rheumatology criteria for $\mathrm{OA}$ of the knee, ${ }^{13}$ with at least five of the following features: knee pain, knee joint tenderness, no palpable warmth over the knee, minimal stiffness ( $<30$ minutes), normal acute phase measures (erythrocyte sedimentation rate and $\mathrm{C}$ reactive protein levels), and negative test for rheumatoid factor. All had normal knee joint radiographs. None had a history of clinically significant trauma to the target joint. The early nature of OA was defined at arthroscopy, and all patients demonstrated evidence of chondropathy with clearly defined fibrillation of articular cartilage. ${ }^{14}$ All patients gave written consent to for an arthroscopic examination and synovial biopsy to be carried out. Synovial tissue samples from patients with late OA were obtained at the time of knee joint arthroplasty. All had clinical and radiographic features of advanced OA. None had a history of inflammatory

Abbreviations: COX, cyclo-oxygenase; DAB, 3,3'-diaminobenzidine; FLS, fibroblast-like synoviocyte(s); HPF, high powered field; ICAM, intercellular adhesion molecule; IL, interleukin; OA, osteoarthritis; PBS, phosphate buffered saline; $\mathrm{PGE}_{2}$, prostaglandin $\mathrm{E}_{2} ; \mathrm{RA}$, rheumatoid arthritis; TNF $\alpha$, tumour necrosis factor $\alpha$; VEGF, vascular endothelial growth factor 
arthritis. The study was approved by the institutional ethics committee.

\section{Arthroscopy and synovial biopsy}

Arthroscopy was performed under local anaesthetic, a technique that is well tolerated and safe. ${ }^{15}{ }^{16}$ In brief, a $2.7 \mathrm{~mm}$ diameter needle arthroscope was inserted into the knee joint using an inferolateral portal. The three articular compartments of the knee joint were explored. The biopsy specimens were obtained through a superolateral portal after a detailed intra-articular examination. Synovial membrane biopsy specimens were taken under direct visualisation from areas of macroscopically apparent synovial villous hypertrophy, snap frozen in optimal cutting temperature (OCT) embedding medium (Tissue-Tek; Miles Inc, Elkhart, IN) by immersion in liquid nitrogen, and stored at $-70^{\circ} \mathrm{C}$ until processed. Synovial tissue obtained from patients with late OA was selected by the orthopaedic surgeon. Efforts were made to ensure that tissue was selected from areas demonstrating gross synovial hypertrophy. If hypertrophy was not apparent, tissue samples were randomly selected. The tissue samples were immediately transferred to the rheumatology laboratory, where they were snap frozen in OCT embedding medium by immersion in liquid nitrogen and stored until use.

\section{Immunohistochemistry}

Before staining, the slides were thawed at room temperature for 15 minutes and then fixed in acetone for 10 minutes. A standard three stage immunoperoxidase technique was used. All reagents were diluted in freshly prepared phosphate buffered saline (PBS; pH 7.4, $25^{\circ} \mathrm{C}$ ) (Sigma Chemical Co Ltd, Poole, UK). Sections were incubated in a humidified chamber throughout the procedure. Normal serum $(0.5 \%)$ from the same species as the secondary biotinylated antibody was applied to the tissue sections for 15 minutes. After washing in PBS, then blotting away the excess moisture, the primary monoclonal antihuman CD4 (Clon MT310; $5 \mu \mathrm{g} / \mathrm{ml} 1: 20$ dilution) or CD68 (Clon EBM1 1; $2.15 \mu \mathrm{g} / \mathrm{ml} \mathrm{1:200} \mathrm{dilution)}$ (Dako Ltd, High Wycombe, UK) antibodies were added to the section for 1 hour at room temperature to elucidate the inflammatory cell infiltrate. Antibodies to human vascular endothelial growth factor (VEGF; $4 \mu \mathrm{g} / \mathrm{ml} 1: 50$ dilution) (Santa Cruz Biotechnology, Santa Cruz, CA, USA), factor VIII (Clon $\mathrm{F} 8 / 86 ; 2.45 \mu \mathrm{g} / \mathrm{ml} \mathrm{l:100} \mathrm{dilution)} \mathrm{(Dako),} \mathrm{and} \mathrm{inter-}$ cellular adhesion molecule (ICAM)-1 $\quad(0.25 \mu \mathrm{g} / \mathrm{ml} \quad 1: 400$ dilution) (Serotec Ltd, Oxford, UK) were used to detect new blood vessel formation and adhesion molecule expression.

A polyclonal anti-NF- $\kappa B l(p 50)$ antibody $(4 \mu \mathrm{g} / \mathrm{ml} \quad 1: 50$ dilution) (Santa Cruz Biotechnology), and a monoclonal anti-Rel A (p65) antibody $(5 \mu \mathrm{g} / \mathrm{ml} \quad 1: 200$ dilution) (Pharmingen Int, San Diego, CA, USA) were used to quantify the nuclear localisation staining of the two activated subunits of NF- $\kappa \mathrm{B}$. Anti-tumour necrosis factor $\alpha(\mathrm{TNF} \alpha ; 4 \mu \mathrm{g} / \mathrm{ml} \mathrm{l:50}$ dilution) and anti-interleukin l (ILl $\beta ; 5 \mu \mathrm{g} / \mathrm{ml} \mathrm{l:40} \mathrm{dilution)}$ (Santa Cruz Biotechnology) antibodies were used to quantify the expression of cytokines. Anti-human cyclo-oxygenase (COX)-1 (10 $\mu \mathrm{g} / \mathrm{ml} \mathrm{l:20} \mathrm{dilution)} \mathrm{and} \mathrm{COX-2}(2.5 \mu \mathrm{g} / \mathrm{ml} \mathrm{l:80}$ dilution) antibodies (Santa Cruz Biotechnology) were used to quantify the expression of cyclo-oxygenases.

After a further washing step, biotinylated secondary antibody was added for 30 minutes followed by horseradish peroxidase conjugated avidin-biotin complex for another 30 minutes (Vectastain kit, Vector Laboratories, Burlingame, CA, USA). Hydrogen peroxide (GPR) (Merck Ltd, Poole, England) 3\% in distilled water was applied for 7 minutes to quench endogenous peroxide, and the tissue was then washed with distilled water. Colour was developed with 3,3'-diaminobenzidine (DAB) (Sigma Chemical Co. Ltd., Poole, England). A $1 \mathrm{ml}$ frozen aliquot of DAB solution was thawed and added to $9 \mathrm{ml}$ PBS with $20 \mu \mathrm{l}$ hydrogen peroxide added immediately before use, yielding a $0.0625 \% \mathrm{DAB}$ and $0.03 \%$ hydrogen peroxide solution. This was added to the tissue sections and left for 13 minutes. The colour reaction was stopped after washing the sections in tap water. Finally, sections were washed serially in water ( 3 minutes), Mayer's haemalum (2 minutes), water (3 minutes), industrial methylated spirits $70 \%$ and $90 \%$ (BP chemicals Ltd, Hull, UK) (10 minutes). This was followed by two washes of 10 minutes each in $100 \%$ industrial methylated spirits, then xylene (AnalaR, Merck Ltd, Poole, UK) for 10 minutes. DPX mountant (Merck) was placed on top of the tissue to allow the cover slips (Chance Propper Ltd, Warley, UK) to adhere. Negative control experiments were performed by using immune absorbed serum, isotype matched irrelevant antibodies, and by omitting the primary antibody.

\section{Quantitative analysis}

Quantitative analysis was performed on all synovial tissue samples. Details of the analytical methods have been previously published. ${ }^{17}{ }^{18} \mathrm{~A}$ single assessor (MJB), who was unaware of the category of OA tissue, systematically examined all sections throughout their entire area. A Leitz Wetzlar Dialux 20 microscope was used to examine the sections under $\times 400$ magnification and a reticule fitted into one of the eyepieces of the microscope allowed analysis of the tissue with reference to high power fields (HPFs). A cell was regarded as exhibiting positive staining if a nucleus was identified in association with appropriate staining.

In the lining layer the numbers of CD68+, NF- $\mathrm{BB}+$, or RelAt cells were expressed as a percentage of the total number of cells counted, up to a maximum of 300 cells per section. In the sublining area, up to 100 HPFs (range 5-100) were examined for the presence of CD4+, CD68+, NF- $\kappa \mathrm{Bl}+$, and RelA+ cells. The numbers of ICAM-1+, TNF $\alpha+$, ILl $\beta+$, COX-1+, and COX-2+ cells were counted throughout the synovium. Scoring the sections was achieved by counting the number of positively staining cells per HPF and using a conversion factor based on the area of the HPF; the final result was expressed as cells $/ \mathrm{mm}^{2}$. The total number of blood vessels was counted and expressed as the number/HPF. A semiquantitative score (0-4) was used to evaluate VEGF expression in the synovium. The staining was individually evaluated, giving values from 0 to 4 in the lining and sublining layers, and in blood vessels $(0$, minimal positive cells; 1 , positive cells scattered throughout the tissue; 2 , same as 1 with some areas of aggregation; 3 , widespread positivity with more areas of aggregation; 4, same as 3 with areas of dense aggregation). The total score derived from the sum of the three areas was taken as the measure of VEGF expression.

\section{Synovial cell cultures}

Tissue samples from patients with early and late OA were minced and incubated with $4 \mu \mathrm{g} / \mathrm{ml}$ collagenase type II (Worthington Biochemical, USA) in culture RPMI 1640 medium with L-glutamine (Gibco BRL, Life Technologies, UK) for 2 hours. After centrifugation, cells were plated in $25 \mathrm{~cm}^{2}$ culture flasks and grown in medium supplemented with 1 M HEPES buffer (Gibco BRL), 20\% fetal calf serum (Bioclear, UK), penicillin ( $100 \mathrm{U} / \mathrm{ml})$ and streptomycin (100 $\mathrm{U} / \mathrm{ml}$ ), and $2500 \mu \mathrm{g} / \mathrm{ml}$ fungizone/amphotercin B (Gibco $\mathrm{BRL})$ at $37^{\circ} \mathrm{C}$ in a humidified atmosphere of $95 \%$ air $/ 5 \%$ $\mathrm{CO}_{2}$ as previously described. ${ }^{19}$ Cells were used at passage 2. Synoviocytes were grown in serum-free medium for 24 hours. 
Table 1 Immunohistological measures of inflammation in OA synovial tissue

\begin{tabular}{lllr}
\hline Measure & Early & Late & p Value \\
\hline Lining layer & $4.0(1.9)$ & $2.3(1.0)$ & 0.011 \\
CD4+ & $181.2(86.2)$ & $105.8(43.0)$ & 0.017 \\
CD68+ & $280.6(59.9)$ & $171.9(58.1)$ & $<0.001$ \\
Factor VIII & $9.8(1.8)$ & $7.6(2.3)$ & 0.010 \\
VEGF & $8.3(2.2)$ & $4.8(2.7)$ & 0.001 \\
ICAM-1 & $438.1(116.7)$ & $159.9(56.7)$ & $<0.001$ \\
TNF $\alpha$ & $431.2(101.6)$ & $210.4(64.5)$ & $<0.001$ \\
IL1 $\beta$ & $542.0(102.1)$ & $202.5(36.0)$ & $<0.001$ \\
COX-1 & $216.3(102.6)$ & $218.1(79.4)$ & 0.48 \\
COX-2 & $312.8(114.6)$ & $233.8(50.7)$ & 0.04 \\
NF-kB1 & $252.2(49.1)$ & $163.4(47.7)$ & $<0.001$ \\
RelA & $134.2(48.4)$ & $87.9(19.8)$ & 0.015 \\
\hline
\end{tabular}

Results are expressed as mean (SD). Lining layer values represent the cell depth. Factor VIII represents the number of blood vessels/HPF. VEGF is expressed as the sum of three semiquantitative scores (0-4) derived from the lining and sublining layers, and blood vessels. CD4+, CD68+, ICAM$1+, \mathrm{IL} 1 \beta+, \mathrm{TNF} \alpha+, \mathrm{COX}-1$ and $2+, \mathrm{NF}-\mathrm{\kappa B} 1+$, and RelA+ cells are expressed as number of cells $/ \mathrm{mm}^{2}$.

\section{Enzyme linked immunosorbent assay (ELISA)}

To determine the amount of prostaglandin $\mathrm{E}_{2} \quad\left(\mathrm{PGE}_{2}\right)$ released, synovial cells extracted from four different patients with early OA and four with late stage OA, were plated in 12 wells. Depleted OA synovial cells were stimulated with recombinant human ILI $\beta$ (Calbiochem, Darmstadt, Germany), TNF $\alpha$ (Calbiochem), or IL6 (R\&D Systems, Oxford, UK) at a final concentration of $10 \mathrm{ng} / \mathrm{ml}$ for 6 hours. After incubation, supernatants were collected and stored at $-70^{\circ} \mathrm{C}$ for further detection of $\mathrm{PGE}_{2}$ levels. $\mathrm{PGE}_{2}$ determinations were performed in duplicate using a commercial $\mathrm{PGE}_{2}$ enzyme immunoassay kit and following the indications of the manufacturer (Assay Designs Inc, Ann Arbor, MI, USA).

\section{Statistical analysis}

Comparison of means was by independent Student's $t$ test. A Bonferonni correction was performed. Values of $p<0.05$ were considered significant. Intraobserver variability was determined on three occasions, after measurement of each variable in half of the samples was completed, over several months. The mean coefficients of variation were $<8 \%$ for all variables.

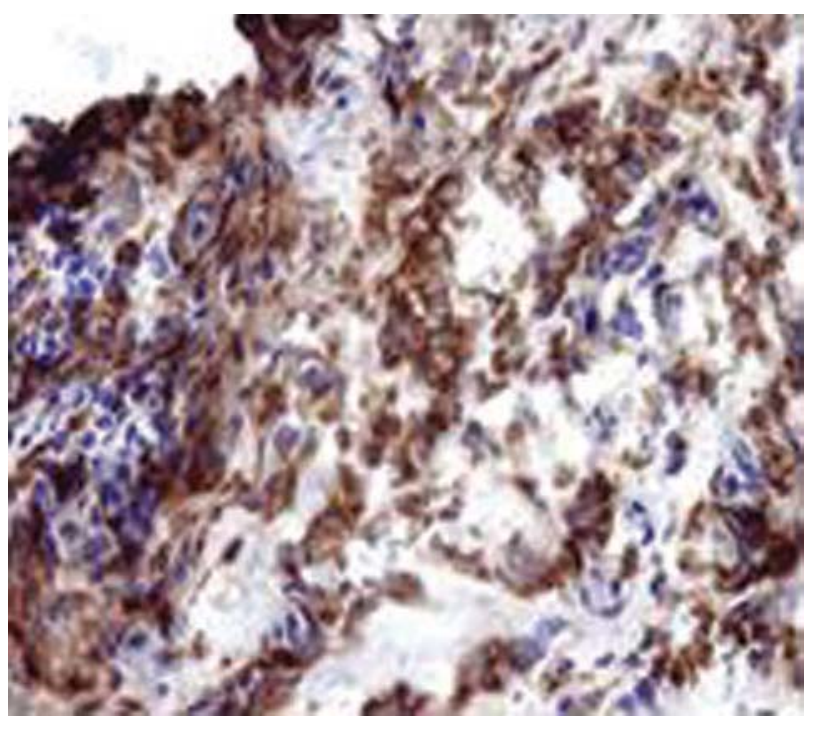

Figure 1 Photomicrographs of synovial tissue from a patient with early $\mathrm{OA}$, demonstrating infiltration by CD68+ mononuclear cells (magnification $\times 100$ ).

\section{RESULTS}

\section{Clinical details}

Ten patients with early OA, aged between 46 and 74 years (mean 63.4), were evaluated. Knee symptoms had been present for $<1$ year. All were taking occasional simple analgesic drugs. None were receiving non-steroidal antiinflammatory drugs at the time of biopsy, and none had received an intra-articular corticosteroid injection. Synovial tissue was also obtained from 15 patients with late OA, aged between 67 and 83 years (mean 74.7). All were receiving analgesic drugs before surgery, and seven were taking nonsteroidal anti-inflammatory drugs. None had received intraarticular corticosteroids within 4 months of surgery. The laboratory variables at the time of surgery were not systematically recorded.

\section{Inflammation in synovial tissue from patients with early and late OA}

Selected immunohistological features of inflammation were quantified in the synovial tissue samples (table 1). Early OA tissues exhibited significantly greater lining layer thickness with a mean cell depth of 4.0, compared with 2.3 in late OA $(p=0.011)$. Similarly, the intensity of both CD4+ T cell and CD68+ macrophage infiltration was significantly greater in early OA $(p=0.017$ and $<0.001$, respectively). Figure 1 demonstrates prominent macrophage infiltration in synovial tissue from a patient with early OA.

Table 1 also compares manifestations of vascular proliferation and activation in synovial tissue from patients with early and late OA. Blood vessels, identified by positive factor VIII staining, were significantly more numerous in early OA tissue samples $(p=0.01)$. In addition, VEGF expression, a marker of vascular proliferation, was significantly greater in early OA $(p=0.001)$. Finally, the adhesion molecule ICAM- 1 , which is expressed on vascular endothelial cells, as well as on synoviocytes and macrophages, was expressed more abundantly in early OA tissues $(p<0.001)$. Figure 2 demonstrates prominent vascularity in synovial tissue from a patient with early OA.

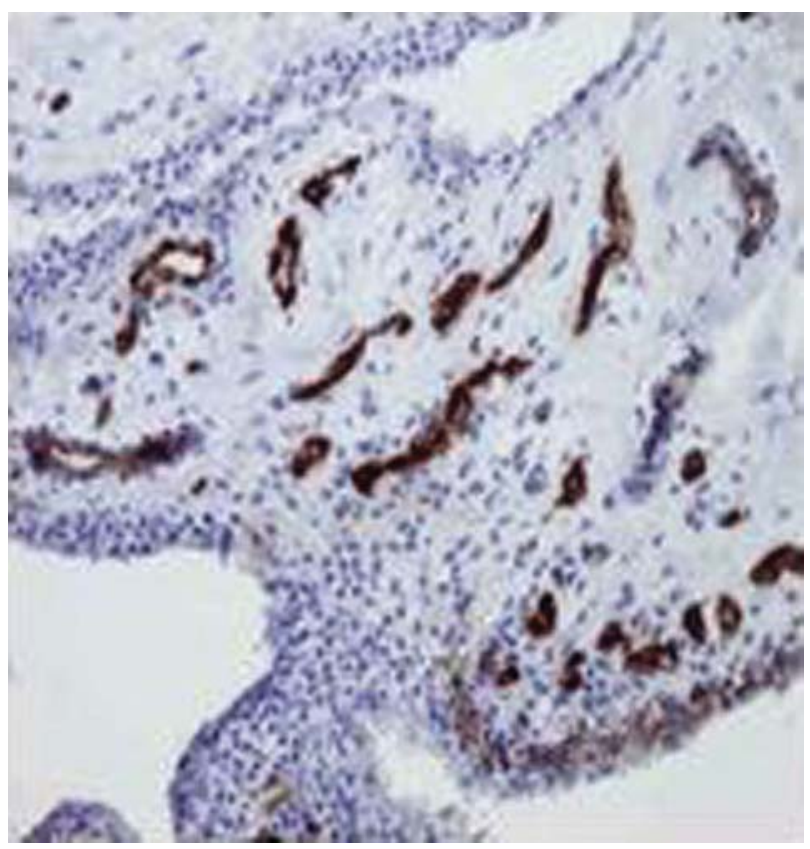

Figure 2 Photomicrograph of synovial tissue from a patient with early $\mathrm{OA}$, demonstrating factor $\mathrm{VIII+}$ endothelial cells (magnification $\times 100$ ). 


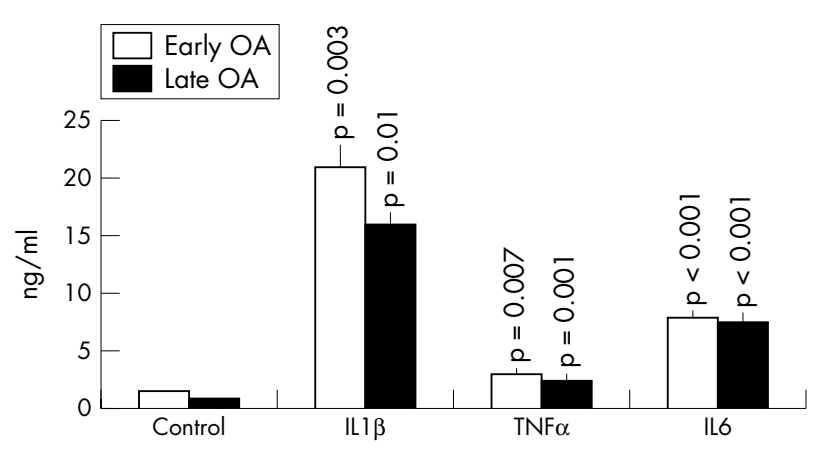

Figure $3 \quad \mathrm{PGE}_{2}$ production by isolated synoviocytes from patients with early and late OA. PGE 2 levels were measured after stimulation of synoviocytes by ILI $\beta, T N F \alpha$, and IL6, and were compared with unstimulated control cultures. The results represent the mean (SE) values from four experiments.

Significantly greater numbers of cells producing both TNF $\alpha$ and ILl $\beta$ were found in early OA $(p<0.001)$ (table 1$)$. The mean numbers of cells expressing COX-1 were similar in early and late OA. However, the number of cells expressing COX-2 was significantly greater in early OA $(p=0.04)$. COX2 expression was seen both in the lining and sublining layers in early OA tissues.

Finally, the NF- $\kappa \mathrm{Bl}$ and RelA subunits were abundantly expressed in all of the synovial tissue samples examined. There were significantly more NF- $\mathrm{KBl}+$ and RelA+ cells in early OA than in late OA $(\mathrm{p}<0.001$ and 0.015 , respectively) (table 1). The NF- $\mathrm{kBl}$ subunit was expressed on endothelial cells, on many of the infiltrating perivascular cells, and on the cells accumulating in the synovial lining layer. The RelA subunit was less widely expressed and present predominantly on endothelial cells, and on occasional sublining and lining layer cells.

\section{In vitro production of $\mathrm{PGE}_{2}$ by isolated synoviocytes from patients with early and late $O A$}

The manifestations of synovial tissue inflammation were quantifiably different in early and late OA. Experiments were performed to determine if synoviocyte populations isolated from patients with early and late OA were also functionally different. Cultured fibroblast-like synoviocytes (FLS) were stimulated with IL1 $\beta, \mathrm{TNF} \alpha$, or IL6, and $\mathrm{PGE}_{2}$ production was measured in four experiments. Thus, IL1 $\beta$ stimulation of FLS from patients with both early and late OA resulted in significantly more $\mathrm{PGE}_{2}$ production than unstimulated control cultures $(p=0.003$ and 0.01 , respectively) (fig 3 ). Similarly, TNF $\alpha$ and IL6 stimulation resulted in significantly more $\mathrm{PGE}_{2}$ production than with controls, in both early $(\mathrm{p}=0.007$ and $<0.001$, respectively $)$ and late $(\mathrm{p}=0.001$ and $<0.001$, respectively) OA FLS cultures. Of interest, there were no differences between early and late OA FLS cultures in cytokine-induced $\mathrm{PGE}_{2}$ production, suggesting that synoviocytes from patients with early and late OA were functionally similar.

\section{DISCUSSION}

In this study, synovial tissue inflammation in the symptomatic knee joints of patients with early OA, and in the knee joints of patients undergoing arthroplasty, was quantified and compared. The early OA tissue samples were selected from patients with recent onset knee pain, normal radiographs, and arthroscopic features of early articular cartilage degeneration. There were no clinical or laboratory features of inflammatory arthritis. Mononuclear cell infiltration, blood vessel formation, and the expression of proinflammatory mediators and nuclear transcription factors were overexpressed in early OA.

The observation that synovial tissue from patients with early OA demonstrated more features of inflammation than late OA appeared to contrast with some previous studies. $^{782021}$ The explanation for the apparent discrepancy is unclear, but may be related to differences in patient and tissue selection, or to the quantification techniques that were employed. For example, in one previous immunohistochemical study of early OA, patients were selected from sports medicine and orthopaedic clinics, were considerably younger, and many were without knee pain. ${ }^{7}$ Other investigators who completed a cross sectional study of synovial tissue in early OA evaluated seven patients who were categorised as early and 27 as severe OA. ${ }^{8}$ These categories were broadly similar to the early and late OA cohorts evaluated in the present study. A semiquantitative method to measure synovial tissue inflammation was employed. Grade I cellularity (scale 0IV), grade II vascularity, and grade I total inflammatory scores were described in the majority of patients in both the early and severe OA patient groups. ${ }^{8}$ These semiquantitative measures of inflammation were relatively low. The measures of synovial inflammation in both early and late OA that were seen in the present study were also low, and less than those normally described in rheumatoid arthritis (RA). Previous studies from this institution and others that included tissue samples from patients with OA and RA demonstrated infiltrating mononuclear cell populations and proinflammatory mediators in both disorders, which were consistently less abundant in OA..$^{22-28}$

The limitations of applying semiquantitative scoring techniques to the measurement of synovial tissue inflammation have been previously highlighted..$^{21}{ }^{22}$ In the present study, a sensitive quantitative method of scoring synovial tissue inflammation was employed. Significant differences between early and late OA were consistently demonstrated for the infiltrating mononuclear cell populations and the expression of several proinflammatory mediators. It is unlikely that the observations reported in this study are spurious. Where possible, areas of macroscopic synovial hypertrophy were selected for biopsy in both patient groups, which might have increased the likelihood of demonstrating microscopic inflammation.

Infiltration of synovial tissue by mononuclear cell populations, proliferation of new blood vessels, and increased expression of several critical molecules, including cytokines, angiogenic factors, adhesion molecules, and inducible COX are characteristic of chronic synovitis in inflammatory arthritis. In this study, synovial tissue from patients with RA and other inflammatory arthropathies was not included for comparison. The principal observation reported here was not that the intensity of synovitis in OA might be similar to that of inflammatory arthropathies, but that the intensity of inflammation in OA was greatest during the early phase.

To determine whether synovial cell populations from patients with early and late OA were functionally different, isolated synoviocytes were cultured with a range of different proinflammatory cytokines. Cytokine-induced $\mathrm{PGE}_{2}$ production by FLS from patients with early and late OA was significantly greater than that produced by normal FLS, but no differences between early and late OA were observed. The absence of functional differences between FLS isolated from patients with early and late OA suggests that increased mononuclear cell infiltration and the overexpression of proinflammatory mediators in early OA represent microenvironmental differences in synovial tissue at different phases of OA.

It is likely that overexpression of inflammatory mediators in early OA reflects increased activation of interrelated 
pathophysiological pathways that contribute to progressive cartilage degradation in some patients. The importance of synovitis in the pathophysiology of $\mathrm{OA}$ is increasingly recognised, although inflammation may not be the primary mechanism in all. ${ }^{11} 29$ Longitudinal studies employing arthroscopy, synovial tissue analysis, and sensitive imaging modalities will be required to determine if the intensity of synovitis plays a critical part in progressive joint damage, and if targeted inhibition of synovitis in early generalised OA may limit the rates of progressive cartilage degradation and functional impairment.

\section{ACKNOWLEDGEMENTS}

MJB was supported by a grant from the European Commission: QLK6-CT-1999-02072.

\section{Authors' affiliations}

M J Benito, D J Veale, O FitzGerald, B Bresnihan, Department of Rheumatology, Education and Research Centre, St Vincent's University Hospital, Dublin, Ireland

W B van den Berg, Department of Rheumatology, University Medical Centre Nijmegen, Nijmegen, The Netherlands

\section{REFERENCES}

1 Peat G, McCarney R, Croft P. Knee pain and osteoarthritis in older adults: a review of community burden and current use of primary health care. Ann Rheum Dis 2001;60:91-7.

2 Felson DT, Zhang Y. An update on the epidemiology of knee and hip osteoarthritis with a view to prevention. Arthritis Rheum 1998;41:1343-55.

3 Bullough P. Pathology of osteoarthritis. In: Hochberg MC, Silman AJ, Smolen JS, Weinblatt ME, Weisman MH, eds. Rheumatology. Edinburgh: Mosby, 2003:1835-45

4 Loeuille D, Toussaint F, Champigneulles J, Grossin L, Blum A, CharyValckenaere I, et al. Evaluation of synovial inflammation in knee OA: histological correlation [abstract]. Arthritis Rheum 2002;46(suppl):S566.

5 lagnocco A, Coari G. Usefulness of high resolution US in the evaluation of effusion in osteoarthritic first carpometacarpal joint. Scand J Rheumatol 2000;29:170-3

6 Ayral X, Ravaud P, Bonvarlet J-P, Simmonet J, Lecurieux R, Nguyen M, et al. Arthroscopic evaluation of post-traumatic patello-femoral chondropathy J Rheumatol 1999;26:1140-7.

7 Myers SL, Brandt KD, Ehlich JW, Braunstein EM, Shelbourne KD, Heck DA, et al. Synovial inflammation in patients with early osteoarthritis of the knee. J Rheumatol 1990;17:1662-9.

8 Smith MD, Triantafillou S, Parker A, Youssef PP, Coleman M. Synovial membrane inflammation and cytokine production in patients with early osteoarthritis. J Rheumatol 1997;24:365-71.

9 Young L, Katrib A, Cuello C, Vollmer-Conna U, Bertouch JV, RobertsThomson PJ, et al. Effects of intraarticular glucocorticoids on macrophage infiltration and mediators of joint damage in osteoarthritis synovial membranes. Arthritis Rheum 2001;44:343-50.

10 Sharif M, Elson CJ, Dieppe PA, Kirwan J. Elevated serum C-reactive protein levels in osteoarthritis. Br J Rheumatol 1997;36:140-1.
11 Spector TD Hart DJ, Nandra D, Doyle DV, Mackillop N, Gallimore JR, et al. Low-level increases in C-reactive protein are present in early osteoarthritis of the knee and predict progressive disease. Arthritis Rheum 1997;40:723-7.

12 Sowers MF, Jannausch M, Stein E, Jamadar D, Hochberg M, Lachance L. Creactive protein as a biomarker of emergent osteoarthritis. Osteoarthritis Cartilage 2002; 10:595-601

13 Altman R, Asch E, Bloch D, Bole G, Borenstein D, Brandt K, et al. Development of criteria for the classification and reporting of osteoarthritis. Classification of osteoarthritis of the knee. Diagnostic and Therapeutic Criteria Committee of the American Rheumatism Association. Arthritis Rheum 1986;29:1039-49.

14 Watanabe M, Takeda S, Ikeuchi H, eds. Osteoarthritis. In: Atlas of Arthroscopy, 2nd ed. Tokyo: Igaku-Shoin, 1969:104-13.

15 Veale DJ. The role of arthroscopy in early arthritis. Clin Exp Rheumatol 1999;17:37-8.

16 Kane D, Veale DJ, FitzGerald O, Reece R. Survey of arthroscopy performed by rheumatologists. Rheumatology (Oxford), 2002;41:210-15.

17 Bresnihan B, Cunnane G, Youssef P, Yanni G, FitzGerald O, Mulherin D. Microscopic measurement of synovial membrane inflammation in rheumatoid arthritis: proposals for the evaluation of tissue samples by quantitative analysis. Br J Rheumatol 1998;37:636-42.

18 Cunnane G, Bjork L, Ulfgren A-K, Lindblad S, FitzGerald O, Bresnihan B, et al. Quantitative analysis of synovial inflammation: a comparison between automated and conventional microscopic measurements. Ann Rheum Dis 1999:58:493-9.

19 Murphy EP, McEvoy A, Conneely OM, Bresnihan B, FitzGerald O. Involvement of the nuclear orphan receptor NURR1 in the regulation of corticotrophin-releasing hormone receptor expression and actions in human inflammatory arthritis. Arthritis Rheum 2001;44:782-93.

20 Goldenberg DL, Egan MS, Cohen AS. Inflammatory synovitis in degenerative joint disease. J Rheumatol 1982;9:204-9.

21 Soren A, Cooper NS, Waugh TR. The nature and designation of osteoarthritis determined by its histopathology. Clin Exp Rheumatol 1988;6:41-6.

22 Dolhain RJ, Ter Haar NT, De Kuiper R, Nieuwenhuis IG, Zwinderman AH, Breedveld FC, et al. Distribution of T cells and signs of T-cell activation in the rheumatoid joint: implications for semiquantitative comparative histology. Br J Rheumatol 1998;37:324-30.

23 Youssef PP, Kraan M, Breedveld F, Bresnihan B, Cassidy N, Cunnane G, et al. Quantitative microscopic analysis of inflammation in rheumatoid arthritis synovial membrane samples selected at arthroscopy compared with samples obtained blindly by needle biopsy. Arthritis Rheum 1998;41:663-9.

24 Johnson BA, Haines GK, Harlow LA, Koch AE. Adhesion molecule expression in human synovial tissue. Arthritis Rheum 1993:36:137-46.

25 Farahat MN, Yanni G, Poston R, Panayi GS. Cytokine expression in synovial membranes of patients with rheumatoid arthritis and osteoarthritis. Ann Rheum Dis 1993;52:870-5.

26 Sawai T, Mikami Y, Kurasono Y. Expression of adhesion molecules, intercellular molecule (ICAM)-1 and lymphocyte function associated antigen (LFA)-1 in the synovial tissues of rheumatoid arthritis (RA). Ryumachi 1994;34:854-62.

27 Ballara S, Taylor PC, Reusch P, Marme D, Feldmann M, Maini RN, et al. Raised serum vascular endothelial growth factor levels are associated with destructive change in inflammatory arthritis. Arthritis Rheum 2001;44:2055-64

28 Benito MJ, Murphy E, Murphy EP, van den Berg WB, FitzGerald O, Bresnihan $B$. Increased synovial tissue NF- $\mathrm{KB} 1$ expression at sites adjacent to the cartilage-pannus junction in rheumatoid arthritis. Arthritis Rheum 2004;50:1781-7.

29 Haywood L, McWilliams DF, Pearson Cl, Gill SE, Ganesan A, Wilson D, et al. Inflammation and angiogenesis in osteoarthritis. Arthritis Rheum 2003;48:2173-7

30 Shibakawa A, Aoki H, Masuko-Hongo K, Kato T, Tanaka M, Nishioka K, et al. Presence of pannus-like tissue on osteoarthritic cartilage and its histologic character. Osteoarthrits Cartilage 2003;11:133-40. 